\title{
Traffic Congestion Issues, Perceptions, Experience and Satisfaction of Car Drivers/Owners on Urban Roads
}

\author{
Reena Majid Memon ${ }^{1 \mathrm{a}}$, Ravindar Kumar Khiani' ${ }^{2}$, Sajjad Ali ${ }^{3}$, Tamkeena Mustafa ${ }^{1 \mathrm{~b}}$, \\ Yasira Naeem Pashatc
}

RECEIVED ON 06.02.2019, ACCEPTED ON 03.05.2019

\begin{abstract}
Traffic congestion is a major issue of Asian megacities which causes the irritation, anger and frustrations among drivers and owners of vehicles during driving in these cities. This paper aims at understanding traffic congestion issues from the perception and experiences of car drivers and owners and their satisfaction level concerning accessibility of circulation within urban roads of Karachi. The issues addressed in this respect are road construction, traffic flow, road crossing, shopping malls along roads, traffic blockage due to VIP movement, congestion during school timing, animal presence on roads, traffic police behavior, marriage halls along the roads, peak hour traffic jams, traffic jams during sociopolitical and religious rallies, road disputes, traffic congestion due to young inexperienced drivers, alternate road availability and pedestrian bridges. The method of investigating these issues is through $\mathbf{4 2}$ questionnaire surveys with car drivers and car owners from June to October 2018 on urban roads of Karachi. The analysis of feedback from respondents showed that, more than $90 \%$ respondents were satisfied with construction of pedestrian bridges and annoyed with sociopolitical and religious rallies on main urban roads. More than $80 \%$ respondents were satisfied with marriage halls along the roads, felt congestion during peak hours and preferred alternate routes to go home. More than 70\% agreed that, young and inexperienced drivers cause traffic congestion and felt unsatisfied and displeased with disputes on the streets among residents, traffic police and drivers. More than $60 \%$ respondents were satisfied with the road construction but annoyed with VIP protocol and felt congestion during school timings and quite uncomfortable while crossing the road. More than $50 \%$ respondents were unsatisfied with shopping malls on both sides of the road, presence of animals on main roads and behavior of traffic police during traffic jams. Finally, concerning traffic flow the respondents were equally divided in their perception. Thus this research presents a detailed perspective of people regarding traffic congestion issues in Karachi for the appropriate response by decision makers of urban transport planning and urban traffic management institutions in city.
\end{abstract}

Keywords: Urban Roads, Car Driving, Congestion, Traffic Management.

\section{INTRODUCTION}

$\mathrm{T}$ The traffic congestion is an issue of concern for car drivers and owners driving on urban roads. It causes irritation, anger and frustration among drivers and owners of vehicles during regular driving on urban roads of megacities. It seems the main reason of congestion is unplanned roads where the culture of driving by the owners and drivers of cars is not considered [1]. The other reason is the planning process of cities where road network is not properly maintained.

The city expands in haphazard manner where proper attention is not paid on congestion issues. As a

\footnotetext{
${ }^{1}$ Department of Architecture and Planning, Dawood University of Engineering and Technology, Karachi, Sindh, Pakistan, Email: ${ }^{a}$ reenamemon09@gmail.com (Corresponding Author), barch_tamkeena01@ hotmail.com, carch.yasira@gmail.com

${ }^{2}$ Department of Architecture and Planning, NED University Engineering and Technology, Karachi, Sindh, Pakistan. Email: rkrkhian@ neduet.edu.pk

${ }^{3}$ Department of Civil Engineering, NED University of Engineering and Technology, Karachi, Sindh, Pakistan. Email:sajiad.ali@neduet.edu.pk

This is an open access article published by Mehran University of Engineering and Technology, Jamshoro under CC BY 4.0 International License.
} 
repercussion the urban roads remain unattended for longer periods of time. In the case of Karachi, the development of signal free corridors caused increase in traffic flow but barred the pedestrians from road use which caused a conflict among car drivers and pedestrians. It results in failure of dealing with traffic congestion and each day one million Pak. Rupees are wasted due to traffic congestion in Karachi [2].

The other fact of the matter is the poor discipline of traffic on major urban roads where drivers drive on wrong way. The one way and two-way roads also get blocked due to this behavior. As a repercussion traffic flow gets affected on urban roads, overcrowding takes place and road traffic situation deteriorates [3]. The problems further complicate when traffic police remains unable to enforce traffic rules and control the car drivers [4]. Other causes of traffic congestion is unavailability of mass transit facilities and unstoppable increase in car population [5]. This problem becomes further complicated with socioeconomic situation of the citizens and cultural practices of the people where car driving becomes a symbol of pride and using public transport is considered as below standard practice. Another aspect of congestion is the old-fashioned management of traffic where drivers are not properly controlled to follow traffic rules and regulations [6].

The traffic police usually does a brilliant job on major busy urban roads for optimizing traffic flow, however, the focus is not paid on the traffic signals due to electronic control. This creates congestion on intersections especially, when electronic signals are not working properly [7]. The less manpower and budget for traffic management institutions is another issue of traffic congestion. The traffic management infrastructure requires huge amount of investment as per ratio of traffic volume increase in the city [8]. The substructure of traffic management shall be provided by considering and analyzing increase of vehicles and bottlenecks of congestion and expected growth of logjams on urban roads of city [9]. The major obstacle in developing countries is the institutional corruption and red tape of bureaucracy which striped the actual progress to solve the traffic congestion related issues and construct megaprojects for urban transportation management.
In a recent study related to problem of traffic congestion in Qasimabad, Hyderabad it is identified via correlation analysis that driving behaviors of drivers are inter-dependent while they drive. The study recommended to enhance the role of institutions in dealing with traffic congestion issues and stressed upon integrating the practice of land use planning and urban transport for traffic management [10].

The existing practices of understanding and analyzing the issues of traffic congestion in different countries impart quite different approaches. For instance, in United States of America, congestion is perceived as traffic block when the average speed reduces on urban freeways for few minutes during week days. The congestion measures they use are based on how much miles a vehicle travels in an hour? What was the average speed of vehicle? How many miles and hours a person travelled on an urban freeway? [11].

In South Korea traffic congestion is recognized when the speed of vehicles reduces and congestion of traffic remains for longer periods of time on daily basis and this pattern continues for more than a month's observation of traffic flow [12]. In Japan they acknowledge congestion of traffic if the speed of travelling reduces on their freeways and onekilometer-long rush of traffic occurs. Secondly, if the people i.e. drivers have to stop after every kilometer for few minutes and then flow starts again, then, this repeated pattern of traffic flow is called congestion on the urban roads of Japanese cities [13]. In developing countries like Pakistan there is high car ownership, which causes congestion on their urban roads and the approach they take is to provide primary and secondary level transportation infrastructure i.e. road widening and constructing flyovers [14]. The provision of transport infrastructure is not the solution and there is a need to explore the traffic congestion issue from different perspectives. For instance, the perception of people about traffic congestion issues, the experience of drivers and car owners running their vehicles on urban roads and the gender based analysis of satisfaction level of different users in a fast growing megacity like Karachi, Sindh, Pakistan. 
This paper explores the potential traffic congestion issues, perception of people i.e. car owners and drivers, their experiences and satisfaction level on urban roads of megacity Karachi. The issues addressed in this respect are road construction, traffic flow, road crossing, shopping malls along roads, traffic blockage due to VIP movement, congestion during school timing, animal presence on roads, traffic police behavior, marriage halls along the roads, peak hour traffic jams, traffic jams during sociopolitical and religious rallies, road disputes, traffic congestion due to young inexperienced drivers, alternate road availability and pedestrian bridges.

\section{THEORETICAL BACKGROUND}

The theoretical background is established through review of literature concerning perceptions of traffic congestion issues, experiences of traffic congestions and satisfaction of car drivers and owners.

\subsection{Perceptions of Traffic Congestion}

The perception of traffic congestion by drivers and owners of cars is quite significant aspect to investigate due to several reasons. The traffic congestion affects the mood, physiography and task performance of commuters because they spend a sizeable time of their days travelling from home to workplace and vice versa [15]. It may exert pervasive effects on their lives especially traffic situation of rush hour are potentially quite stressful due to imposed delay and it also instigates hostility [16]. The behavioral aftereffects of this emotional demand of driving are impaired road performance and social or communication deficit when arrive at home or at work [17]. The long term exposure to traffic congestion is often occurred in the form of elevated heart rate as physiological residue and anger as psychological excess in behavior [18].

The perception of traffic congestion is realized by car drivers through abstract visualizations without real time experience of driving and such perception changes with time by driving experience on urban roads [19]. The owners of the cars are more sensitive towards safety of their vehicles during traffic congestions and the drivers usually remain in the Mehran University Research Journal of Engineering and Technology, Vol. 39, No. 3, July 2020 [p-ISSN: 0254-7821, e-ISSN: 2413-7219] mode of competition with other drivers to get out earlier. The response of male driver and a female driver to traffic congestion perception is also a matter of detailed investigation. It would be interesting to note how the gender response to traffic congestion perception is and whether both genders have a similar perception or a different insight.

\subsection{Experience of Traffic Congestion}

The experience of drivers and car owners about traffic congestion at urban roads can be multivariate and worth exploring due to different reasons. The typical male or female car owners have different sense of belongingness to the vehicles and at the same time drivers also have different sense of attachment and experience of traffic congestion. Similarly, the typical male or female has different driving patterns if compared with drivers of vehicles. Concerning driving patterns aggressive driving is a worldwide phenomenon due to traffic congestion when it comes to both male and female drivers. It depends upon their personality traits, neuroticism and anger management [20]. The age of driver, learning of driving and driving experience trigger casual, random or smooth driving patterns [21]. Traffic monitoring is the tool for analyzing traffic congestions and experiences of drivers of different types and their driving patterns. The traffic monitoring of urban roads has identified that, the car drivers experience high noise levels and air pollution on congested busy urban roads [22]. The road traffic noise and congestion causes an experience of annoyance. Whereas, among all noise generating sources the road traffic noise is a major source followed by factories and machines that cause irritation, anger, frustration and displeasure on the part of drivers and vehicle owners [23]. The consequence of exposure to high level traffic noise during traffic congestion can cause severe stress on auditory and nervous system of drivers especially due to noise of motorcycles and rickshaws on urban roads [24]. One of the major experience for car drivers is erratic driving behavior of motorcycle, rickshaw and large vehicles [25]. The heterogeneous traffic mix with congestions is a tough experience of car drivers. Similarly, frequent interruption of heavy traffic volumes with higher speeds cause an aggressive behavior among car drivers. The greater number of 
trucks along with buses also increase the loudness of traffic noise as a common experience of car drivers [26]. The reaction to these multivariate traffic congestion experiences by the drivers and car owners need further examination to explore other such dimensions in different urban contexts.

\subsection{Satisfaction of Car Drivers/Owners}

The satisfaction has diverse range of interpretations concerning car drivers and car owners' experience of traffic congestions. It is related with road conditions, flow of traffic, land use along road, socio-political conditions and drivers' behavioral pattern. In generic terms, everyone knows what satisfaction is until people are asked to give a definition of satisfaction, then it seems, that nobody knows what satisfaction is [27]?

The satisfaction is mostly related to the feelings of a person. The issue with satisfaction is that when users get efficient provision services from a service provider they feel happy and satisfied, however, inefficient service leads to dissatisfaction [28]. There are two popular concepts of satisfaction i.e. the satisfaction that existed within a person due to internal peace and the satisfaction that is generated through real world experience of available services. The satisfaction via experience of available services is worth exploring concept [29]. It is because when experience of available road services deliver satisfaction to drivers, the quality of service becomes sustainable and it would maintain the regular ridership of car drivers and owners on urban roads.

\section{$2.4 \quad$ The Hypotheses}

The literature review of traffic congestion issues, perceptions, experiences and satisfaction leads us to propose in this paper a conceptual model (as shown in Fig. 1) with reference to contextual study of traffic congestions on urban roads of Karachi. Through this conceptual model causal relationships are explored among traffic congestion issues and perceptions, experiences, satisfaction of car drivers and owners on urban roads of Karachi. In this respect five different hypotheses were developed as outlined below:

Hypothesis-1: The perception of car drivers and owners is negatively affected by congestion issues. The reason behind it is the road conditions, flow of traffic, land use along road, socio-political conditions and drivers' behavioral pattern affects car driver and owners.

Hypothesis-2: The satisfaction of car drivers and owners is negatively affected by congestion issues. The reason behind this is lower satisfaction of car drivers and owners when they perceive traffic congestion affects the physiological and sociopsychological health.

Hypothesis-3: Traffic congestion issues have a negative effect on experience. This is because car drivers and owners would have worse perception and lower satisfaction when they regularly experience worse monitoring of traffic congestion on urban roads.

Hypothesis-4: The driving experience of car drivers and owners on congested urban roads positively affected their satisfaction level. The reason behind it is the learning experience of car drivers and owners to deal with traffic congestion and getting used to it with time.

Hypothesis-5: The perception of car drivers and owners is positively affected with satisfaction through experience. The reason behind it is that, drivers and owners of cars gets satisfied with their driving experience and available services on the urban roads.

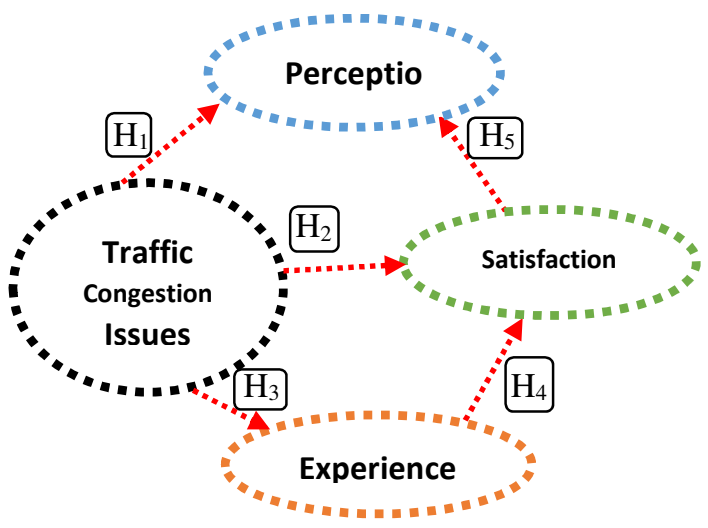

FIG. 1: TRAFFIC CONGESTION ISSUES PERCEPTIONS, EXPERIENCES \& SATISFACTION: A CONCEPTUAL MODEL

\subsection{Conceptual Model}

The proposed conceptual model (Fig. 1) establishes the hierarchical equation of traffic congestion issues 
with their perceptions, satisfaction and experiences through the lens of car drivers and owners' opinions and perspectives. This is a technique used to examine the situation of traffic congestion on urban roads of Karachi and test hypotheses related to perception, experience and experience of traffic congestion issues.

The conceptual model has both observed variables and extracted unseen dormant variables. The methodology of this research was that, many observed variables were used to extract few unseen dormant variables through covariation technique. In this way the number of observed variables turned into few number of extracted unseen dormant variables [30]. Graphically, a rectangle is used to specify the hypothesis and an oval to display the variable in the model (Fig.1). Additionally, an arrow is marked to indicate the straight influence of one variable to another. In this way a pivotal association is shown among the two different variables.

The traffic congestion issues, perception, satisfaction, and experience are the four unseen dormant variables depicted in this model to find out the straight influence among them through outlined one to five hypotheses. In this regard a questionnaire was developed and survey was conducted among car drivers and car owners to get pointers to gauge the relation among these unseen dormant variables. The Pearson chi-square tests and symmetric measures analytical methods are used to evaluate the proposed conceptual model. In order to have a satisfactory model evaluation the sample size of at least 420 questionnaires is stated as adequate.

\section{MATERIALS AND METHODS}

\subsection{Case Study Area}

Karachi is the $6^{\text {th }}$ largest world city around the globe [31]. The megacity Karachi is the capital of Sindh province and located at the Arabian Sea coastline of Pakistan. The megacity Karachi is prime economic, industrial, financial, cultural, philanthropic, educational, political and urban hub of Pakistan. Karachi also serves as a transport hub, with two largest seaports and airports. Millions of passengers fly annually from the Jinnah International Airport of Karachi and use the busiest urban roads of this megacity. Many local and foreign airlines bring and depart these passengers as well as cargo shipments. The Karachi metropolitan region is spread over 3,530 square kilometers with more than 1700 kilometers long road space which makes it a second largest conurbation [32]. The Karachi is a multiethnic sociocultural, sociopolitical, plural and resilient city with people from various backgrounds contribute to its urban growth and expansion of urban roads with their permanent settlements.

According to population census in 1998 Karachi's population was 9,339,023 inhabitants that is increased up to $14,910,352$ inhabitants in 2017 with $37.37 \%$ gross increase [33]. The current urbanized area of city is $3,780 \mathrm{~km}^{2}$. The density of population in Karachi is above 24,000 persons/sq.km. It is equivalent to 63,000 persons/sq. mi. This makes it high density city [34]. The trade and commerce activities in Karachi are of very huge scale with passengers and cargo movements spread up to central Asian countries and neighboring countries of Iran, Afghanistan and China [35].

In the year 2012, the last study for Karachi transportation improvement was carried out by JICA Japan International Cooperation Agency (JICA) [36] in which transportation projects were planned and executed to improve the traffic flow. This included new transport infrastructure constructions on urban roads from S.I.T.E. to Shahrah-e-Faisal, North Karachi to Shahrah-e-Faisal, and Safooran Goth to Saddar. However, during 2015, the total registered vehicles in Karachi increased exponentially. Now there are more than 2.7 million motorcycles on urban roads of Karachi [37]. In addition, the driving license holders of rickshaws, motorcycles, cars and other vehicles in Karachi are less than forty percent which indicates an alarming situation [38]. Due to these facts traffic congestion is still the major challenge for Karachiites and therefore urban roads of Karachi were selected as the case study area for this research.

Total 42 locations were identified with the problem of traffic congestion and conducted a questionnaire survey on these locations (Fig. 2). 


\subsection{The Data Collection Survey}

A car can typically carry on an average at least six adults. The focus was on drivers and the owners of the cars. The special attention was given to involve women drivers or owners of the cars as female drivers now quite commonly drive cars in Karachi. The working women and single mothers usually drop their kids in the schools and then go to their offices. In afternoons they take the children from school and spend the lunch hour from 1:00pm to 2:00pm with their children. And then again join the offices and return in the evenings around 5:00pm to 7:00pm. Various field surveys were undertaken to ask questions from car drivers and owners during afternoons and in evenings from June to October 2018.

The data collection team involved at least six members to fill the questionnaires. The questionnaire was developed through a pilot survey based on interviews in Urdu and Sindhi language. Then, the questionnaire was developed in English and also translated it in Urdu and Sindhi language to ensure understanding of surveyors and consistency between the English, Urdu and Sindhi versions. The questionnaire had two sections. Section one had the questions to collect information about personal where the respondent felt comfortable. The surveyors information of respondents with their driving routines on urban roads of Karachi. The section two had the questions to collect information about their perception, experience and satisfaction while driving their cars on urban roads of Karachi. All the items in section two of the questionnaire given the respondents two options of yes or no or agree or disagree as the interview time was purposefully limited to min five to max ten minutes during rush hour or at the time of actual congestion.

The Fig.2 points out the locations of survey in Karachi, Sindh, Pakistan. The survey was conducted on major urban roads, near intersections and recreational places of the city. The size of survey sample was not decided earlier but it was dependent on the respondents to give time to fill the questionnaire within the daily available survey time of surveyors. A simple random sampling technique was adopted by the surveyors via requesting every car driver and owner they met to help in filling the survey questionnaire. The surveyors have to conduct quick survey during rush hours and it was depended on the respondents to agree. The surveyors had the target to fill questionnaire from around 500 people but they got consent from only 450 respondents. The surveyors conducted interviews on such locations

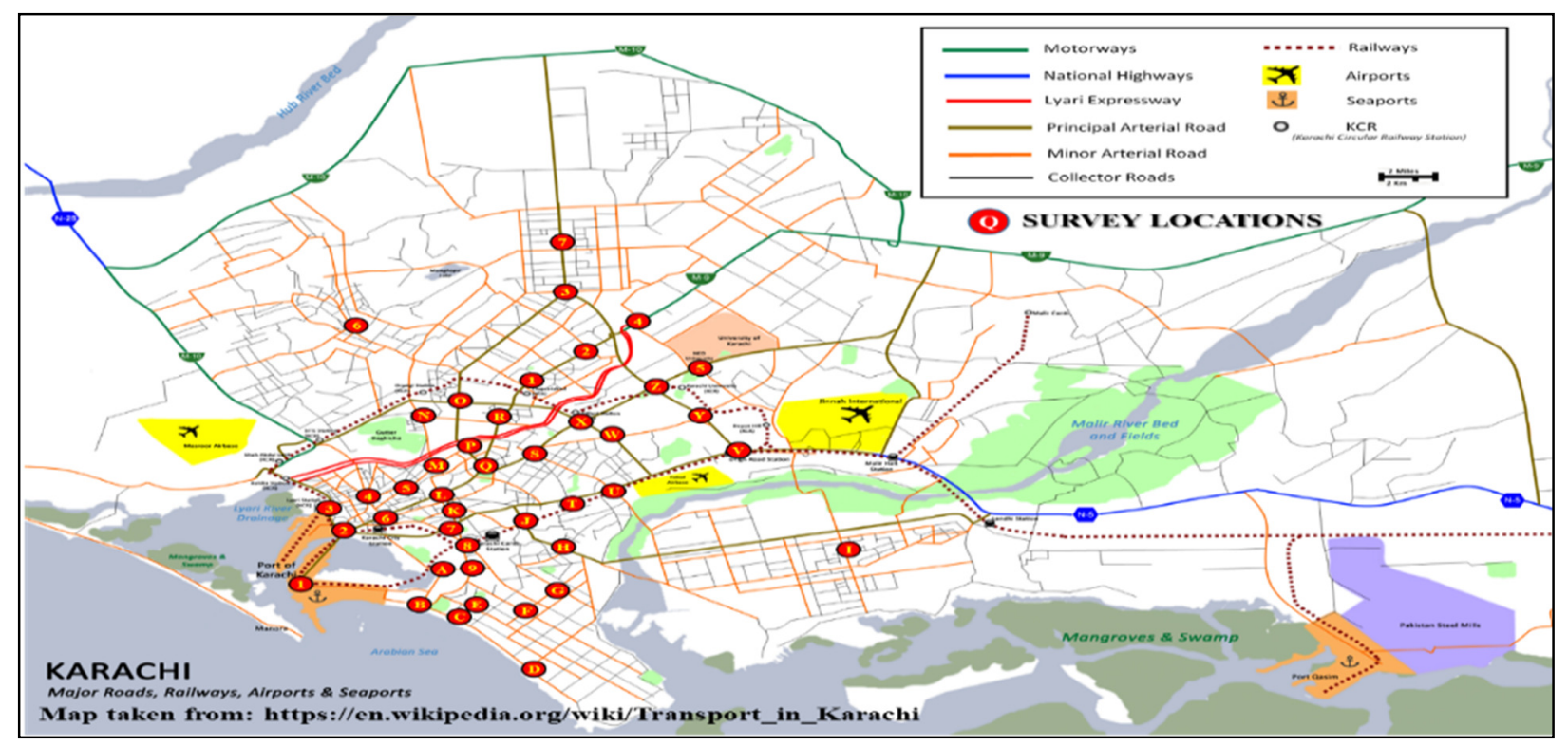

FIG. 2. SURVEY LOCATIONS AT MAJOR URBAN ROADS AND INTERSECTIONS OF KARACHI, SINDH, PAKISTAN. 
where the respondents felt comfortable. The surveyors used to carry ticky packs of biscuits as a token of appreciation for the respondents to participate in the survey. On an average, it took five to ten minutes to fill the survey form.

\subsection{The Data Analysis}

After evaluating the total 450 questionnaires it was established that, only 420 questionnaires are useful for further processing of data. Initially a table was generated by running SPSS software to find out the general characteristics of respondents in terms of the statistical attributes for each item as reported in Table1.

As per analysis the respondents were aged in four categories. $11.90 \%$ were below 20 years. The majority respondents i.e. $47.62 \%$ were between age group of 21-30 years, $19.05 \%$ were in the age group $31-40.11 .90 \%$ were between age group of 41-50 and only $9.52 \%$ respondents were above 51 years of age. Concerning marital status of respondent's majority were unmarried i.e. $55 \%$ whereas only $45 \%$ respondents were married. Concerning vehicle ownership status majority of respondents i.e. $86 \%$ were the owners of the vehicle/car whereas only $14 \%$ of respondents were the drivers of the car. The experiences of respondents i.e. car owners and drivers regarding vehicle driving were divided in four categories i.e. from one to ten; eleven to twenty; twenty-one to thirty and above thirty-one years of driving experience respectively. The majority respondents i.e. $64.29 \%$ had less than ten years of driving experience. Whereas $23.81 \%$ had less than twenty years of driving experience. The $9.52 \%$ respondents had less than thirty years of driving experience and only $2.38 \%$ respondents had more than 31 years of driving experience as shown in Fig.3.

\subsection{The Model Measurements}

On the day of interview respondents were requested to freely identify the major issues related to traffic

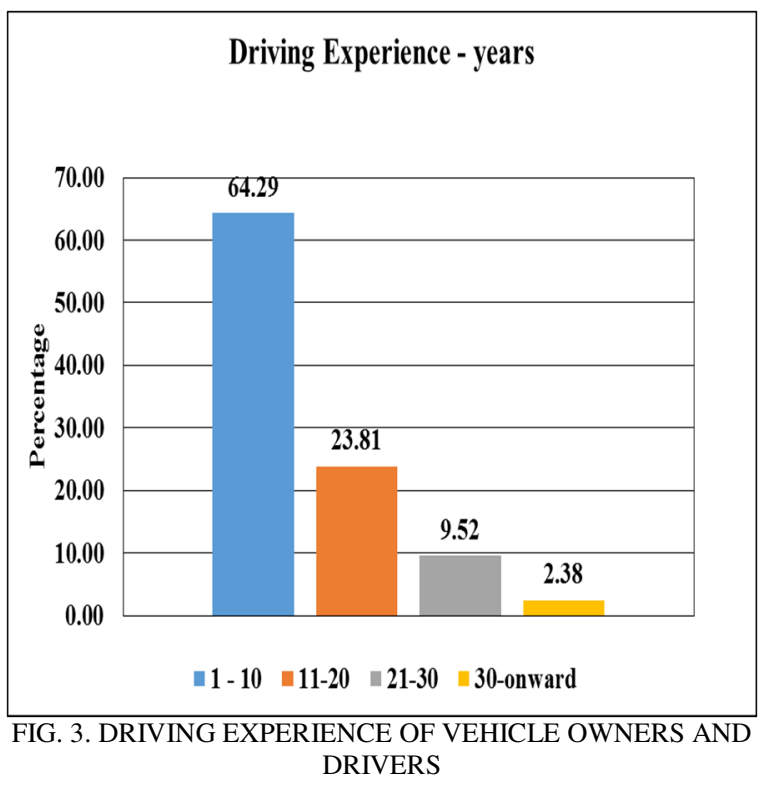

\begin{tabular}{|c|c|c|c|c|c|c|c|c|}
\hline \multicolumn{9}{|c|}{ TABLE 1. DESCRIPTIVE STATISTICS OF RESPONDENTS } \\
\hline Items & Age & Percent & Mean & $\begin{array}{c}\text { Standard } \\
\text { Error }\end{array}$ & Median & $\begin{array}{c}\text { Standard } \\
\text { Deviation }\end{array}$ & Variance & Range \\
\hline \multirow{5}{*}{ Age } & Below 20 & 0.12 & \multirow{5}{*}{0.20} & \multirow{5}{*}{0.07} & \multirow{5}{*}{0.12} & \multirow{5}{*}{0.16} & \multirow{5}{*}{0.03} & \multirow{5}{*}{0.38} \\
\hline & $21-30$ & 0.48 & & & & & & \\
\hline & $31-40$ & 0.19 & & & & & & \\
\hline & $41-50$ & 0.12 & & & & & & \\
\hline & 51 above & 0.10 & & & & & & \\
\hline \multirow{2}{*}{$\begin{array}{c}\text { Marital } \\
\text { Status }\end{array}$} & Married & 0.45 & \multirow{2}{*}{0.50} & \multirow{2}{*}{0.05} & \multirow{2}{*}{0.50} & \multirow{2}{*}{0.07} & \multirow{2}{*}{0.005} & \multirow{2}{*}{0.10} \\
\hline & Unmarried & 0.55 & & & & & & \\
\hline \multirow{2}{*}{$\begin{array}{c}\text { Vehicle } \\
\text { Ownership }\end{array}$} & Driver & 0.14 & \multirow{2}{*}{0.50} & \multirow{2}{*}{0.36} & \multirow{2}{*}{0.50} & \multirow{2}{*}{0.51} & \multirow{2}{*}{0.26} & \multirow{2}{*}{0.71} \\
\hline & Owner & 0.86 & & & & & & \\
\hline \multirow{4}{*}{$\begin{array}{l}\text { Experience } \\
\text { of Driving }\end{array}$} & $1-10$ & 0.64 & \multirow{4}{*}{0.25} & \multirow{4}{*}{0.14} & \multirow{4}{*}{0.17} & \multirow{4}{*}{0.28} & \multirow{4}{*}{0.08} & \multirow{4}{*}{0.62} \\
\hline & $11-20$ & 0.24 & & & & & & \\
\hline & $21-30$ & 0.10 & & & & & & \\
\hline & 30-onward & 0.02 & & & & & & \\
\hline
\end{tabular}


congestion on urban roads of Karachi. These responses were then classified through an induction deduction method into fifteen different issues as shown in Fig. 4.

The respondents identified the issues of traffic congestion as road construction $(\mathrm{N}=230)$, traffic flow $(\mathrm{N}=300)$, road crossing $(\mathrm{N}=195)$, shopping malls on both sides of roads $(\mathrm{N}=230)$, VIP protocol $(\mathrm{N}=320)$, school timings $(\mathrm{N}=400)$, animal presence on road $(\mathrm{N}$ $=155)$, traffic police $(\mathrm{N}=200)$, marriage halls on both sides of road $(\mathrm{N}=245)$, peak hours $(\mathrm{N}=395)$ sociopolitical and religious rallies $(\mathrm{N}=410)$, disputes by residents, drivers, traffic police $(\mathrm{N}=190)$, young less experienced drivers $(\mathrm{N}=412)$, use of alternate routes $(\mathrm{N}=278)$ and availability of the pedestrian bridges. Thus, we obtained quite mixed responses on traffic congestion issues from total 420 respondents because different number of respondents identified different issues.

From these responses the seriousness of issues was analyzed by calculating the percentage of respondents for each issue to find out the hierarchy of traffic congestion issues as reported in Table 2.

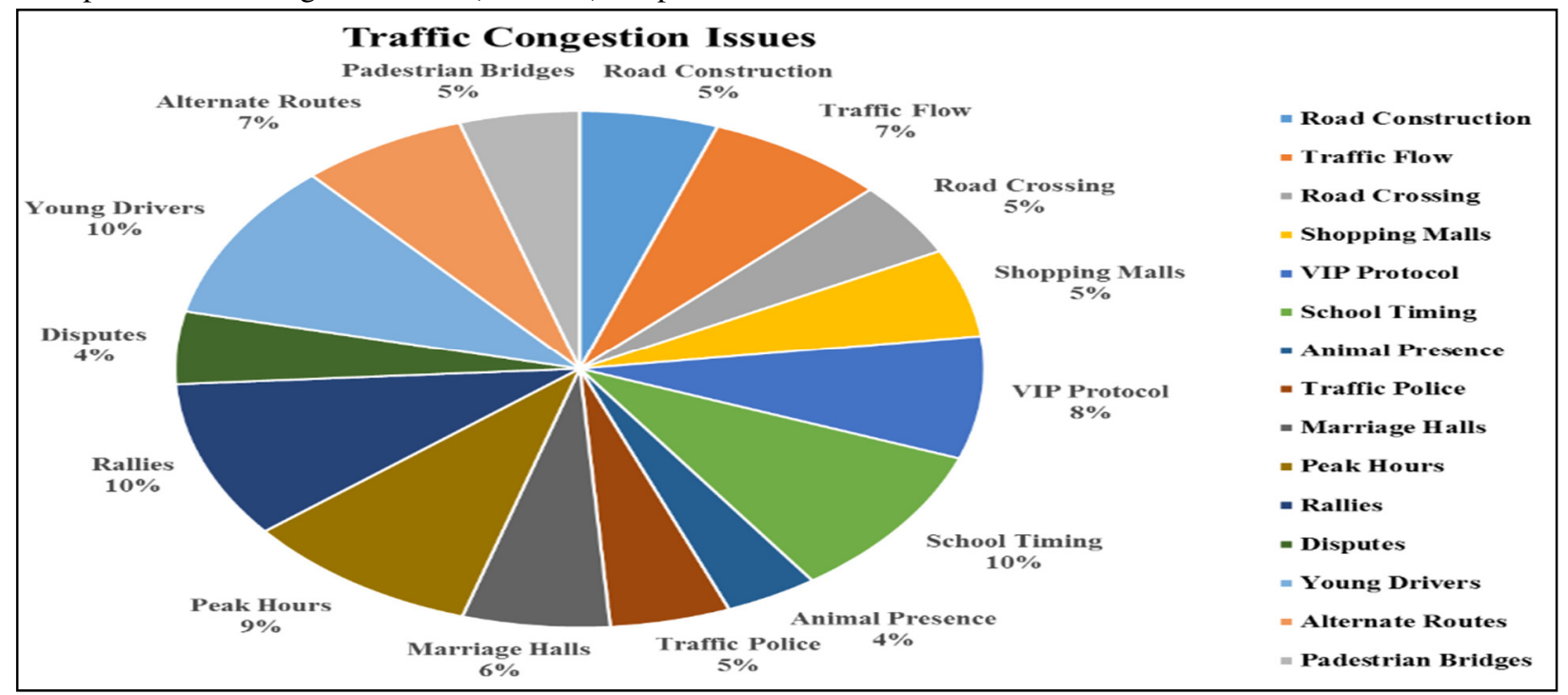

FIG. 4. ISSUES OF TRAFFIC CONGESTION AS IDENTIFIED BY CAR OWNERS AND DRIVERS

\begin{tabular}{|c|c|c|c|}
\hline \multicolumn{4}{|c|}{ TABLE 2: THE SERIOUSNESS OF TRAFFIC CONGESTION ISSUES AS IDENTIFIED BY RESPONDENTS } \\
\hline No. & Traffic Congestion Issues & No. of Responses & Seriousness of Issue (\%) \\
\hline 1. & Animal Presence & 155 & 36.90 \\
\hline 2. & Disputes & 190 & 45.24 \\
\hline 3. & Road Crossing & 195 & 46.43 \\
\hline 4. & Traffic Police & 200 & 47.62 \\
\hline 5. & Pedestrian Bridges & 200 & 47.62 \\
\hline 6. & Road Construction & 230 & 54.76 \\
\hline 7. & Shopping Malls & 230 & 54.76 \\
\hline 8. & Marriage Halls & 245 & 58.33 \\
\hline 9. & Alternate Routes & 278 & 66.19 \\
\hline 10. & Traffic Flow & 300 & 71.43 \\
\hline 11. & VIP Protocol & 320 & 76.19 \\
\hline 12. & Peak Hours & 395 & 94.05 \\
\hline 13. & School Timing & 400 & 95.24 \\
\hline 14. & Rallies & 410 & 97.62 \\
\hline 15. & Young Drivers & 412 & 98.10 \\
\hline
\end{tabular}




\begin{tabular}{|c|l|c|c|c|}
\hline \multicolumn{5}{|c|}{ TABLE 3: STATISTICS OF POTENTIAL UNSEEN DORMANT VARIABLES OF CONCEPTUAL MODEL } \\
\hline No. & $\begin{array}{l}\text { Questions related to Traffic Congestion Issues, Perception, } \\
\text { Experience and Satisfaction }\end{array}$ & $\begin{array}{c}\text { Unseen } \\
\text { Dormant } \\
\text { Variable }\end{array}$ & $\begin{array}{c}\text { Yes } \\
(\%)\end{array}$ & $\begin{array}{c}\text { No } \\
(\%)\end{array}$ \\
\hline 1. & Are you satisfied with the road construction and traffic congestion? & Satisfaction 1 & 69.05 & 30.95 \\
\hline 2. & Are you satisfied with traffic flow during traffic congestion? & Satisfaction 2 & 50.00 & 50.00 \\
\hline 3. & $\begin{array}{l}\text { Do you feel comfortable while road crossing during traffic } \\
\text { congestions? }\end{array}$ & Experience 1 & 33.33 & 66.67 \\
\hline 4. & $\begin{array}{l}\text { Do you feel shopping malls on both sides of road cause traffic } \\
\text { congestion? }\end{array}$ & Perception 1 & 47.62 & 52.38 \\
\hline 5. & Do you think VIP protocol create traffic congestion on roads? & Perception 2 & 66.67 & 33.33 \\
\hline 6. & Do you think during the school timing traffic congestion increases? & Perception 3 & 66.67 & 33.33 \\
\hline 7. & $\begin{array}{l}\text { Did you experienced presence of animals on roads and cause traffic } \\
\text { congestion? }\end{array}$ & Experience 2 & 59.52 & 40.48 \\
\hline 8. & $\begin{array}{l}\text { Are you satisfied with performance of traffic police during traffic } \\
\text { congestion? }\end{array}$ & Satisfaction 3 & 42.86 & 57.14 \\
\hline 9. & $\begin{array}{l}\text { Do you think marriage halls on both sides of road cause traffic } \\
\text { congestion? }\end{array}$ & Perception 4 & 88.10 & 11.90 \\
\hline 10. & Are you satisfied with traffic congestion during peak hours? & Satisfaction 4 & 88.10 & 11.90 \\
\hline 11. & $\begin{array}{l}\text { Do you think political/religious/social rallies cause and increase } \\
\text { traffic congestions? }\end{array}$ & Perception 5 & 92.86 & 7.14 \\
\hline 12. & $\begin{array}{l}\text { Do you think disputes on the roads by residents/traffic } \\
\text { police/drivers caused traffic congestion? }\end{array}$ & Experience 3 & 23.81 & 76.19 \\
\hline 13. & $\begin{array}{l}\text { Do you think young and less experienced drivers cause traffic } \\
\text { congestion? }\end{array}$ & Perception 6 & 73.81 & 26.19 \\
\hline 14. & $\begin{array}{l}\text { Do you use alternate routes to go to home during traffic } \\
\text { congestion? }\end{array}$ & Experience 4 & 83.33 & 16.67 \\
\hline 15. & $\begin{array}{l}\text { Do you support the idea of making pedestrian bridges on urban } \\
\text { roads with traffic congestion? }\end{array}$ & Perception 7 & 90.48 & 9.52 \\
\hline
\end{tabular}

Table 3 comprehends the statistics of the potential unseen dormant variables of the conceptual model shown earlier. Each unseen dormant variable was evaluated by minimum four pointers where each pointer signifies an entry of questionnaire as responded by car drivers and owners on five point scale. An especial attention was given to perception with more than four pointers due to its significance and an inbuilt duality. Because, perception lead to satisfaction and satisfaction makes alterations and modifications in the thought process and change the perception in totality.

The perception of traffic congestion was evaluated through seven interrelated questions. The first perception related question was about traffic congestion due to shopping malls on both sides of road $47.62 \%$ agreed and $52.38 \%$ disagreed.
Concerning VIP protocol $66.67 \%$ agreed and $33.33 \%$ disagreed as a cause of congestion. Same was the response regarding increase of congestion during school timings $66.67 \%$ agreed and $33.33 \%$ disagreed. About marriage halls on both sides of road as cause traffic congestion $88.10 \%$ agreed and $11.90 \%$ disagreed. The respondents were also asked about the political, religious and social rallies as a cause to increase traffic congestions. The vast majority i.e. $92.86 \%$ agreed and only $7.14 \%$ disagreed. On the question of young and less experienced drivers as cause of traffic congestion $73.81 \%$ agreed and $26.19 \%$ disagreed. On the idea of making pedestrian bridges on urban roads, a vast majority i.e. $90.48 \%$ agreed and only $9.52 \%$ disagreed.

The experiences of traffic congestion was evaluated through four interrelated questions. The experience related first question was about the experience of comfort in road crossing during traffic congestions only $33.33 \%$ agreed and $66.67 \%$ disagreed. 
Concerning experience of animal presence on roads and as cause of traffic congestion $59.52 \%$ agreed while $40.48 \%$ disagreed. Regarding traffic congestion on urban roads of Karachi due to disputes by residents, traffic police or drivers only $23.81 \%$ agreed and $76.19 \%$ disagreed. When respondents were asked about using alternate routes to go to home during traffic congestion $83.33 \%$ agreed and $16.67 \%$ disagreed on using any alternate route.

The satisfaction was evaluated through four interrelated questions. The first satisfaction related question was concerned with user's satisfaction with the road construction and congestion. The remaining questions (satisfaction 2, 3, 4) assessed satisfaction with the traffic flow, performance of traffic police and congestion during peak hours. According to results, $69.05 \%$ respondents were satisfied with road construction and congestion whereas, $30.95 \%$ respondents disagreed. About traffic flow the result shows only $50 \%$ satisfaction. Concerning performance of traffic police only $42.86 \%$ were satisfied and
$57.14 \%$ were not satisfied. Finally, regarding peak hour traffic congestion $88.10 \%$ respondents were satisfied which means they have adopted with the traffic situations and only $11.90 \%$ were not satisfied.

\section{RESULTS AND DISCUSSIONS}

The results of overall contextual variables and latent variables were tested and obtained with the application of Pearson chi-square test and symmetric measures by analyzing the data of car drivers and owners.

The results of all the potential model variables of traffic congestion with respect to car drivers and car owners with their cumulative comparison and standardized effects are presented in aforementioned Table 4. The estimated results of the model based on Pearson chi square values with standardized effects are given below in Fig. 5.

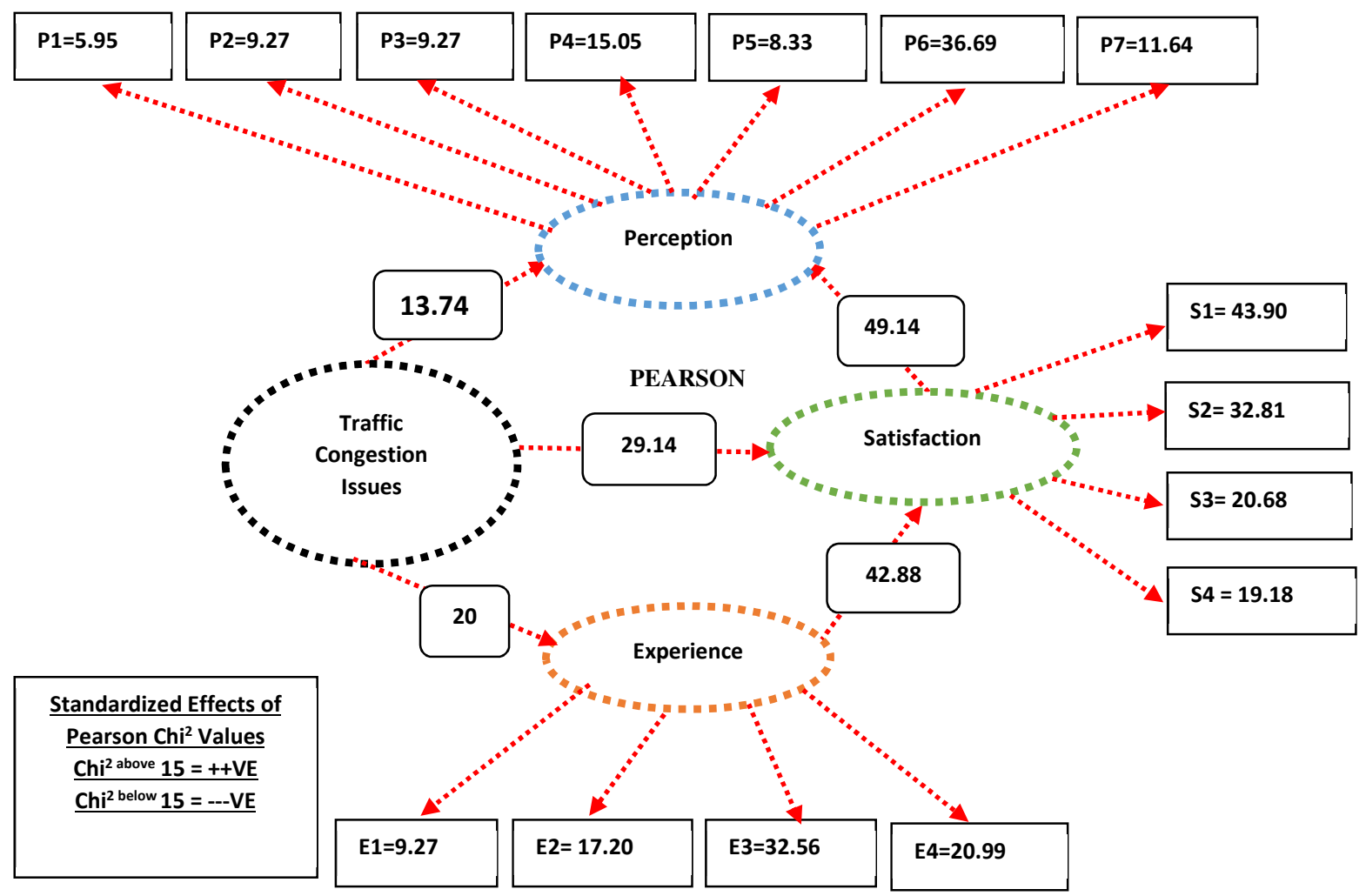

FIG. 5: ESTIMATED RESULTS OF THE MODEL BASED ON PEARSON CHI SQUARE VALUES WITH STANDARDIZED EFFECTS 


\begin{tabular}{|c|c|c|c|c|c|c|c|c|c|c|c|}
\hline \multirow[b]{2}{*}{ No. } & \multirow[b]{2}{*}{ Question } & \multicolumn{2}{|c|}{ Driver } & \multicolumn{2}{|c|}{ Owner } & \multicolumn{2}{|c|}{$\begin{array}{c}\text { Chi-Square } \\
\text { Tests } \\
\end{array}$} & \multicolumn{4}{|c|}{ Symmetric Measures } \\
\hline & & 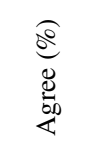 & 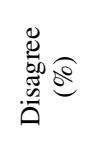 & 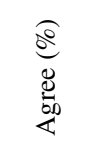 & 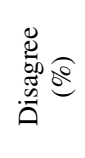 & 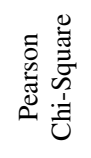 & 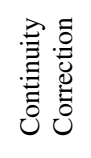 & 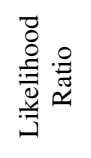 & $\overrightarrow{\bar{a}}$ & 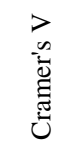 & 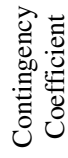 \\
\hline 1. & $\begin{array}{l}\text { Satisfaction with road } \\
\text { construction? }\end{array}$ & 100.00 & 0.00 & 63.89 & 36.11 & 43.90 & 41.50 & 57.87 & -0.47 & 0.47 & 0.42 \\
\hline 2. & $\begin{array}{lr}\text { Satisfaction } & \text { with } \\
\text { traffic flow during } \\
\text { congestion? }\end{array}$ & 83.33 & 16.67 & 44.44 & 55.56 & 32.81 & 31.15 & 34.13 & -0.41 & 0.41 & 0.38 \\
\hline 3. & $\begin{array}{l}\text { Experience while road } \\
\text { crossing in } \\
\text { congestions? }\end{array}$ & 83.33 & 16.67 & 63.89 & 36.11 & 9.27 & 8.32 & 9.43 & -0.22 & 0.22 & 0.21 \\
\hline 4. & $\begin{array}{l}\text { Perception of shopping } \\
\text { malls on both sides of } \\
\text { road \& congestion? }\end{array}$ & 33.33 & 66.67 & 50.00 & 50.00 & 5.95 & 5.27 & 5.99 & 0.17 & 0.17 & 0.17 \\
\hline 5. & $\begin{array}{l}\text { Perception about VIP } \\
\text { protocol } \\
\text { congestion? }\end{array}$ & 83.33 & 16.67 & 63.89 & 36.11 & 9.27 & 8.32 & 9.43 & -0.22 & 0.22 & 0.21 \\
\hline 6. & $\begin{array}{l}\text { Perception } \\
\text { school time traffic } \\
\text { congestion? }\end{array}$ & 83.33 & 16.67 & 63.89 & 36.11 & 9.27 & 8.32 & 9.43 & -0.22 & 0.22 & 0.21 \\
\hline 7. & $\begin{array}{l}\text { Experienced of } \\
\text { animals on roads and } \\
\text { congestion? }\end{array}$ & 83.33 & 16.67 & 55.56 & 44.44 & 17.20 & 15.95 & 17.65 & -0.29 & 0.29 & 0.28 \\
\hline 8. & $\begin{array}{l}\text { Satisfaction with } \\
\text { traffic police in } \\
\text { congestion? }\end{array}$ & 16.67 & 83.33 & 47.22 & 52.78 & 20.68 & 19.32 & 21.30 & 0.32 & 0.32 & 0.31 \\
\hline 9. & $\begin{array}{l}\text { Perception of marriage } \\
\text { halls on both sides of } \\
\text { road and congestion? }\end{array}$ & 100.00 & 0.00 & 86.11 & 13.89 & 15.05 & 12.98 & 20.46 & -0.27 & 0.27 & 0.26 \\
\hline 10. & $\begin{array}{l}\text { Satisfied with peak } \\
\text { hour congestion? }\end{array}$ & 66.67 & 33.33 & 91.67 & 8.33 & 19.18 & 17.67 & 20.31 & 0.31 & 0.31 & 0.30 \\
\hline 11. & $\begin{array}{l}\text { Perception of political/ } \\
\text { religious /social rallies } \\
\text { cause congestions? }\end{array}$ & 100.00 & 0.00 & 91.67 & 8.33 & 8.33 & 6.38 & 11.42 & -0.20 & 0.20 & 0.20 \\
\hline 12. & $\begin{array}{l}\text { Experience of disputes } \\
\text { on roads and } \\
\text { congestion? }\end{array}$ & 0.00 & 100.0 & 27.78 & 72.22 & 32.56 & 30.27 & 43.39 & 0.40 & 0.40 & 0.37 \\
\hline 13. & $\begin{array}{l}\text { Perception of young } \\
\text { drivers } \\
\text { congestion? }\end{array}$ & 100.00 & 0.00 & 69.44 & 30.56 & 36.69 & 34.36 & 48.69 & -0.43 & 0.43 & 0.39 \\
\hline 14. & $\begin{array}{l}\text { Experience to use } \\
\text { alternate routes during } \\
\text { traffic congestion? }\end{array}$ & 100.00 & 0.00 & 80.56 & 19.44 & 20.99 & 18.84 & 28.34 & -0.32 & 0.32 & 0.31 \\
\hline 15. & $\begin{array}{l}\text { Perception about } \\
\text { making pedestrian } \\
\text { bridges on congested } \\
\text { urban roads? }\end{array}$ & 100.00 & 0.00 & 88.89 & 11.11 & 11.64 & 9.62 & 15.89 & -0.24 & 0.24 & 0.23 \\
\hline
\end{tabular}

Fig.5 contains all the chi-square values representing the causal relationships along with standardized effects. The standardized effects were measured on the basis of chi-square values and the number of items in the questionnaire i.e. 15. The principle developed in this respect is that, if the chi-square values went beyond this number of items in the questionnaire and comes above 15 it indicates that there is a positive relationship between the two 
variables. Whereas, if the chi-square value does not cross 15 and comes below this number, it indicates a negative relationship between the two variables. Thus, with this simple principle the causal relationships would be determined.

The results of the model based on Pearson chi square values with standardized effects were estimated by using the data of all respondents on perception, experience and satisfaction with total five hypotheses (H1-H5) and the result of their causal effects identified in Fig. 5.

With relation to traffic congestion issues, Table 5, shows the result of five tested hypotheses with positive, negative, significant and little significant effects on behavioral intentions of the car drivers and owners. In addition, the effect of experience on the satisfaction and the effect of satisfaction on the perception of car drivers and owners is also presented.

The result of first hypothesis (H1) which was concerned with the effect of traffic congestion on perception is given in Table 5. It identified the variable of traffic congestion issues with a path showing its relation with the variable of perception and its Pearson chi $^{2}$ value of 13.75 which is below 15 and supported by the estimated results of the model in Fig. 5. (i.e. $13.74=>\mathrm{Chi}^{2}$ below 15$)$. As mentioned earlier if the chisquare value does not cross 15 and comes below this number, it indicates a negative relationship between the two variables. Thus, this result indicates a significant negative effect of traffic congestion on the perception of car drivers and owners.

The result of second hypothesis (H2) which was concerned with the negative effect of traffic congestion on satisfaction is mentioned in Table. 5. Surprisingly, it was not supported by the construct in the model (i.e. $29.14=>\mathrm{Chi}^{2}$ above 15 ). This result identified a positive and significant effect of traffic congestion on satisfaction. This is because car drivers and owners would have lower satisfaction when they perceive traffic congestion but with experience they get satisfied.

The result of third hypothesis (H3) which was concerned with negative experience of traffic congestion is mentioned in Table. 5. Interestingly, it was also not supported in the model construct (i.e. 20 $=>\mathrm{Chi}^{2}$ above 15 ). Instead, this result suggests a little significant positive effect of traffic congestion on experience. This is because regular experience of congestions on urban roads made the car drivers and owners to get used to it and it is evident that, the result is opposite to what was expected in the hypothesis.

The result of fourth hypothesis (H4) which was concerned with the positive effect of driving experience on satisfaction is mentioned in Table. 5. This model construct is shown to be very true (i.e. $42.88=>\mathrm{Chi}^{2}$ above 15$)$ that driving experience lead to satisfaction. The reason behind this fact is the learning through experience to deal with traffic congestion by drivers and owners of the car.

The result of fifth hypothesis (H5) which was concerned with the positive effect of satisfaction on perception is given in Table. 5. The result indicates that, it was remarkably supported by the construct in the model (i.e. $49.14=>\mathrm{Chi}^{2}$ above 15 ). It designates a

\begin{tabular}{|c|c|c|c|c|c|}
\hline Variables & Path & Variables & $\begin{array}{c}\text { Pearson Chi }{ }^{2} \\
\text { Value } \\
\end{array}$ & $\begin{array}{r}\text { Positive/ Negat } \\
\text { Eff }\end{array}$ & Significant \\
\hline $\begin{array}{c}\text { Traffic Congestion } \\
\text { Issues }\end{array}$ & $\cdots \cdots \cdots$ & Perception & 13.75 & Significant & Negative \\
\hline $\begin{array}{c}\text { Traffic Congestion } \\
\text { Issues } \\
\end{array}$ & $(\cdots, \cdots, \cdots$ & Experience & 20 & Little Significant & \multirow{4}{*}{ Positive } \\
\hline $\begin{array}{c}\text { Traffic Congestion } \\
\text { Issues } \\
\end{array}$ & (........... & Satisfaction & 29.14 & \multirow{3}{*}{ Significant } & \\
\hline Experience & (n...... & Satisfaction & 42.88 & & \\
\hline Satisfaction & .......... & Perception & 49.14 & & \\
\hline
\end{tabular}


direct, significant and positive effect. This result is plausible because satisfied drivers and owners are expected to have experience of driving and their perception of congestion is quite different from dissatisfied users.

These results in the model were further substantiated with an additional analytical discussion about all the observed variables within latent variables i.e. perception (P1-P7), experience (E1-E4) and (S1-S4). Concerning perception of the car drivers and owners the result shows that, shopping malls on both sides of road $\left(\mathrm{P} 1=5.95=>\mathrm{Chi}^{\text {2below }} 15\right), \quad \mathrm{VIP}$ protocol $\left(\mathrm{P} 2=9.27=>\mathrm{Chi}^{\text {2below }} 15\right), \quad$ school time traffic $\left(\mathrm{P} 3=9.27=>\mathrm{Chi}^{\text {2below }} 15\right)$, political $/$ religious $/$ social rallies $\left(\mathrm{P} 5=8.33=>\mathrm{Chi}^{\text {2below }} 15\right)$, making pedestrian bridges $\left(\mathrm{P} 7=11.64=>\mathrm{Chi}^{\text {2below }} 15\right)$, are not significant issues that causes traffic congestion. However, marriage halls on both sides of road $\left(\mathrm{P} 4=15.05=>\mathrm{Chi}^{\text {2above }} 15\right)$ is a little bit and young and less experienced drivers $\left(\mathrm{P} 6=36.69=>\mathrm{Chi}^{2 \text { above }} 15\right)$ are most significant issues that causes traffic congestion on urban roads.

With relation to experience of the car drivers and owners the result shows that, road crossing by pedestrians $\quad\left(\mathrm{E} 1=9.27=>\mathrm{Chi}^{\text {2below }} 15\right)$ is not a significant issue that causes traffic congestion. However, the presence of animals on roads $\left(\mathrm{E} 2=17.20=>\mathrm{Chi}^{2 \text { above }} 15\right)$, disputes on roads $\left(\mathrm{E} 3=32.56=>\mathrm{Chi}^{2 \mathrm{above}} 15\right)$ and using alternate routes $\left(\mathrm{E} 4=20.99=>\mathrm{Chi}^{2 \text { above }} 15\right)$ are direct, significant, issues related to traffic congestion on urban roads. Regarding satisfaction of car drivers and owners the result shows that, road construction $\left(\mathrm{S} 1=43.90=>\mathrm{Chi}^{2 \text { above }} 15\right)$, traffic flow ( $\mathrm{S} 2=32.81=>\mathrm{Chi}^{\text {2above }} 15$ ), traffic police $\left(\mathrm{S} 3=20.68=>\mathrm{Chi}^{2 \text { 2above }} 15\right)$, and peak hours $\left(\mathrm{S} 4=19.18=>\mathrm{Chi}^{2 \text { above }} 15\right)$ are all direct, significant, issues related to traffic congestion on urban roads.

\section{CONCLUSIONS}

Traffic congestion or traffic jam is an issue with very vast variety and some hidden dimensions. It is both a problem and blessing in disguise. It is problem when one is young and inexperienced because it is related to stimulation of human mind and spur its psychology to deal with mechanic modern life or fast moving machines such as cars. This research has taken car as a primary mode of transport on urban roads. Congestion is blessing when one stuck in the traffic jam and socially interact with surroundings and other fellow human beings. It generates arguments among people which belong to variety of socioeconomic backgrounds at a common public domain of urban roads.

Congestion stimulates the brain of every person using urban roads where unknown people discuss and dialogue with each other and argue on the open roads. Congestion makes them democratic and they get aware about their rights on the urban roads. Congestion creates a scenario where competition and competitiveness occurs among unfamiliar people of different socioeconomic levels and their perceptions are shaped when they deal with each other.

Congestion get people a real life experience of ground realities, the available facilities and systems running around the roads. People learn from their experience of congestion the limitation of space, and the relationship of numerous kinds of vehicles for mobility. When traffic flow reduce the speed of a vehicle through controllers and modes of transport, it irritates people which causes behavioral change.

However, running a car on urban roads is overall a very good learning experience of high-tech fast moving machines and traditional modes of transport on the same shared space. With different speeds and intersecting traffic flow the main issue remains the way to deal with it. Which in turn make people realize the fact of life to make both ends meet i.e. the origin and destination with limited time.

The driving experience make people feel alive with a sense of control of a vehicle and being controlled by the traffic controllers. The traffic congestion stimulates different levels of creativity, curiosity and satisfaction in human minds. Congestion make people respect and realize the rights of other people and minimize the differences of us and them.

Congestion creates a class consciousness among people driving their vehicles with a status awareness which further arouses their sense of belongingness. 
Their dissatisfactions with congestion make them take alternate routes, shortcuts, and go on wrong side drive, which in turn creates an urban life drama and determination to win the race of life.

Thus, finally it is to conclude that the effects of traffic congestion issues on perception, experiences and satisfaction were carefully examined with the lens of car drivers and owners on the urban roads. These effects were examined by using a conceptual model and data was collected from the car drivers and car owners in Karachi.

We found that, perception of traffic congestion is negative without the experience of driving on the urban roads. Whereas, experience of driving has the positive effect on satisfaction of car drivers and car owners.

The findings indicated that, there are fifteen different issues related to traffic congestion that, affects the perception, experience and satisfaction of car drivers and car owners driving on urban roads of Karachi. The most significant issue of car drivers and owners with relation to traffic congestion is the young age inexperienced drivers running their vehicles on urban roads.

In relation to perception of car drivers and owners the marriage halls on both sides of road is a significant contributor to traffic congestion. Whereas, experience of animal presence and disputes on urban roads is also a significant sponsor of traffic congestion and lead to take alternative routes. With regard to satisfaction of car drivers and owners about the traffic congestion are traffic flow and traffic police as significant contributors to satisfied users on urban roads.

The study of traffic congestion issues, perception experiences and satisfaction is an initial attempt to understand the complexity within this concept. The depth in this notion need further exploration. For instance, the avenues of further research on traffic congestion issues can be based on six different knowledge domains such as mathematical theories, social theories, economic theories, planning theories, design theories and urban theories. (i) Concerning mathematical theories, it is recommended that traffic congestion shall be related to fluid dynamics, chaos theory, initial butterfly effects etc.

(ii) Regarding social theories, it is recommended that congestion issues may be connected to the concept of social stratification, modernity and class consciousness.

(iii) With respect to economic theories it is recommended that traffic congestion be related to tragedy of commons, road pricing, privatization and public transportation.

(iv) In relation to planning theories it is recommended that communicative approach, advocacy planning, bargaining model, and land use models shall be applied to traffic congestion issues.

(v) It is also recommended that traffic congestion can be intertwined with design theories such as block design, mechanism design, and intelligent design of road space etc.

(vi) Concerning urban theories, it is recommended that traffic congestion shall be explored from the larger macro scale lens of globalization, sustainability, climate change and urban decay etc.

The final recommendation is that, model based approaches in suggested domains of knowledge shall be undertaken by considering modes of transport and road users variety.

\section{ACKNOWLEDGEMENT}

The authors acknowledge the efforts of all the research participants, respondents, reviewers, referees and experts. We thank them for their precious time, suggestions and shared knowledge to help complete this research paper. Special thanks to Ar. Tania Ali Soomro and Dr. Mukesh, NED University of Engineering \& Technology, Karachi, Pakistan, for their valuable guidance to publish this paper in the Mehran University Research Journal of Engineering and Technology.

\section{REFERENCES}

[1] Jain, V., Sharma, A., \& Subramanian, L. "Road traffic 
congestion in the developing world." Proceedings of the 2nd ACM Symposium on Computing for Development pp. 11 Atlanta, GA, United States 11-12 March 2012.

[2] Ali, M. S., Adnan, M., Noman, S. M., \& Rafiqui, S. F. A. "Estimation of traffic congestion cost-a case study of a major arterial in Karachi”. Proceedings of the Fourth International Symposium on Infrastructure Engineering in Developing Countries, IEDC 2013 Procedia Engineering, Elsevier p. 77, 37-44. Karachi, Sindh, Pakistan 2014

[3] Zhang, Z. "Background Analysis of Traffic Law Discipline Construction." Canadian Social Science, Volume 8 No.6, pp.160164. Quebec City, Quebec, Canada. (2012).

[4] Kumar, A., \& Barrett, F. "Stuck in traffic: Urban transport in Africa." AICD World Bank, Background paper, 1. Paris, France 2008.

[5] Zhang, M., \& Wang, L. "The impacts of mass transit on land development in China: The case of Beijing". Research in Transportation Economics, Elsevier Science Direct, Vol. 40 No. 1, pp. 124-133. Beijing, China April 2013.

[6] Kersys, A. "Sustainable urban transport system development reducing traffic congestions costs." Inzinerine Ekonomika-Engineering Economics, Vol. 22 No. 1, pp. 5-13. Kaunas, Lithuania 2011.

[7] Islam, I., Mostaquim, M. E., \& Biswas, S. K. "Analysis of possible causes of road congestion problem in Dhaka City." Imperial Journal of Interdisciplinary Research, Vol. 2 No.12. pp. 42-47, New Delhi India, 2016.
Nash, J. R. "Economic Efficiency versus Public Choice: The Case of Property Rights in Road Traffic Management." Boston College Law Review. Vol. 49, Issue 3. No. 3 pp.673, New York, USA, 2008.

[9] Bel, G., Estache, A., \& Foucart, R. "Transport infrastructure failures in Spain: mismanagement and incompetence, or political capture? Corruption, Grabbing and Development: Real World Challenges." Edward Elgar Publishing Inc. Northampton, Chapter 10, pp.129-139 Massachusetts, USA 2014.

[10] Arain S, Shaikh F, Shaikh MM. "Problem of Traffic Congestion and Correlation Analysis of Driving behaviors in Qasimabad, Hyderabad." Mehran University Research Journal of Engineering and Technology. Volume 36, No. 1, pp139-48 Jamshoro, Sindh. Jan 1, 2017.

[11] Rao, A. M., \& Rao, K. R. "Measuring urban traffic congestion-a review." International Journal for Traffic \& Transport Engineering, Volume 2 No. 4. pp. 286-305, Rosemead, California, USA 2012.

[12] Tan, F., Wu, J., Xia, Y., \& Chi, K. T. "Traffic congestion in interconnected complex networks." Physical Review E, American Physical Society (APS) Vol. 89, No. 6, New York, USA 2014.

[13] Saito, K., Kato, T., \& Shimane, T. "Traffic Congestion and Accident Externality: A Japan-US Comparison." The BE Journal of Economic Analysis \& Policy, Volume 10 No. 1. Berlin, Germany. 2010. 
[14] Uddin, A. "Traffic congestion in Indian cities: Challenges of a rising power." Kyoto of the Cities, Naples, Italy March, 26-28, 2009.

[15] Quddus, M. A., Wang, C., \& Ison, S. G. "Road traffic congestion and crash severity: econometric analysis using ordered response models." Journal of Transportation Engineering, Vol.136 No. 5, pp.424435. Loughborough UK. 2009.

[16] De Palma, A., \& Lindsey, R. "Traffic congestion pricing methodologies and technologies." Transportation Research Part C: Emerging Technologies, Elsevier Science Direct, Vol. 19 No. 6, pp.1377-1399. British Columbia, Canada December 2011.

[17] Zhu, H., Zhu, Y., Li, M., \& Ni, L. M. "SEER: metropolitan-scale traffic perception based on Lossy sensory data." In IEEE INFOCOM 2009 pp. 217-225. IEEE. Waterloo, Canada April 2009.

[18] Hongsakham, W., Pattara-Atikom, W., \& Peachavanish, R. "Estimating road traffic congestion from cellular handoff information using cell-based neural networks and K-means clustering." 5th International Conference on International Electrical Engineering / Electronics, Computer, Telecommunications and Information Technology, 2008. ECTI-CON 2008. Vol. 1, pp. 13-16. IEEE. Krabi, Thailand May 2008.

[19] Park, J., Chen, Z., Kiliaris, L., Kuang, M. L., Masrur, M. A., Phillips, A. M., \& Murphey, Y. L. "Intelligent vehicle power control based on machine learning of optimal control parameters and prediction of road type and traffic congestion." IEEE Transactions on Vehicular Technology, Vol. 58 No.
9, pp.4741-4756. Miyagi, Japan 2009.

[20] Jovanović, D., Lipovac, K., Stanojević, P., \& Stanojević, D. "The effects of personality traits on driving-related anger and aggressive behaviour in traffic among Serbian drivers." Transportation research part F: traffic psychology and behaviour, Vol. 14 No. 1, pp.43-53. Elsevier Science Direct, Serbia 2011.

[21] Borowsky, A., Shinar, D., \& OronGilad, T. "Age, skill, and hazard perception in driving." Accident Analysis \& Prevention, Vol. 42 No. 4, pp.1240-1249. Maryland, USA 2010.

[22] Hoh, B., Gruteser, M., Herring, R., Ban, J., Work, D., Herrera, J. C. \& Jacobson, Q. "Virtual trip lines for distributed privacy-preserving traffic monitoring." In Proceedings of the 6th international conference on Mobile systems, applications, and services pp. 15-28. ACM. New York USA June 2008.

[23] Agarwal, S., \& Swami, B. L. "Road traffic noise, annoyance and community health survey-A case study for an Indian city." Noise and health, Vol. 13 No.53, pp.272. Jaipur, Rajasthan, India 2011.

[24] Mehdi, M. R., Kim, M., Seong, J. C., \& Arsalan, M. H. "Spatio-temporal patterns of road traffic noise pollution in Karachi, Pakistan." Environment international, Elsevier Science Direct, Vol. 37 No.1, pp. 97104. Vernier, Switzerland 2011.

[25] Banerjee, D., Chakraborty, S. K., Bhattacharyya, S., \& Gangopadhyay, A. "Evaluation and analysis of road traffic noise in Asansol: an industrial town of eastern India." International Journal 
of Environmental Research and Public Health, Vol. 5 No. 3, pp.165171. Basel, Switzerland 2008.

[26] Agarwal, S., \& Swami, B. L. "Comprehensive approach for the development of traffic noise prediction model for Jaipur city." Environmental monitoring and assessment, Vol. 172 No.1-4, pp. 113-120. Springer Switzerland 2011.

[27] Giese, J. L., \& Cote, J. A. "Defining consumer satisfaction." Academy of marketing science review, Vol. 1 No.1, pp.1-22. Washington USA. 2000.

[28] Yang, Z., \& Peterson, R. T. "Customer perceived value, satisfaction, and loyalty: The role of switching costs." Psychology \& Marketing, Vol. 21 No. 10, pp.799822. Wiley InterScience, Wiley Periodicals, Inc. New Jersey USA 2004.

[29] Phun, V. K., Kato, H., \& Yai, T. "Traffic risk perception and behavioral intentions of paratransit users in Phnom Penh." Transportation research part F: traffic psychology and behaviour, Vol.55, pp.175-187. Elsevier Science Direct, Phnom Penh Cambodia 2018.

[30] Schreiber, J. B., Nora, A., Stage, F. K., Barlow, E. A., \& King, J. "Reporting structural equation modeling and confirmatory factor analysis results: A review." The Journal of Education Research, Vol. 99 No. 6, pp.323-337. Abingdon Oxford shire UK 2006.

[31] Stanley, B. E. "Going Global: Wannabe World Cities in the Middle East." Contributions in economics and economic history, Vol. 1, pp. 151-170 Wiley Periodicals, Inc. New Jersey USA. 2003.
[32] Qureshi, S. "The fast growing megacity Karachi as a frontier of environmental challenges: Urbanization and contemporary urbanism issues." Journal of Geography and Regional Planning, Vol. 3 No.11, pp.306-321. Berlin Germany 2010.

[33] Niazi, F., \& Azad, A. P. Investigation of Ethnic Diversity in Pakistan: A Case Study of Karachi. Journal of Basic and Applied Sciences, Vol. 14, pp.246-253 Ontario Canada. 2018.

[34] Ilyas, M., Naeem, K., Fatima, U., Nisar, M. I., Kazi, A. M., Jehan, F \& Ahmed, I. "Profile: Health and Demographic Surveillance System in peri-urban areas of Karachi, Pakistan." Gates Open Research, Journal of Public Health Informatics Vol. 10 No.1 pp. 8953 London UK. 2018.

[35] Ali, S. A. "Prospects of Cooperation with Central Asian States." Pakistan Horizon, Vol. 46 No.2, pp.55-70 Karachi, Sindh, Pakistan 1993.

[36] Hasan, A. "Land contestation in Karachi and the impact on housing and urban development." Environment and urbanization, 27(1), 217-230 SAGE Publication London, UK 2015.

[37] Zubair, S., Kazmi, J. H., Jooma, R., Ali, S. S., \& Akhtar, Z. "Impacts of signal free corridors on the incidence of road traffic accidents in Karachi." Journal of Basic \& Applied Sciences, Vol. 11 No.1, pp.244 Karachi, Sindh Pakistan 2015.

[38] Tahir, M. N. "Road safety aspects of motorcycle rickshaws in Pakistan" Doctoral dissertation, Queensland University of Technology. Queensland Australia 2018. 